\title{
DNA Compaction Peptide
}

National Cancer Institute

\section{Source}

National Cancer Institute. DNA Compaction Peptide. NCI Thesaurus. Code C29717.

A synthetic peptide used to formulate and deliver deoxyribonucleic acids (DNA, usually in plasmid form) in gene therapy. The carrier peptides may condense plasmids into nanoparticles with a hydrodynamic diameter ranging from 40 to $200 \mathrm{~nm}$, which are sterically stable for long periods of time. Peptide-based gene delivery systems are used for transfection in a variety of cell lines. ( $\mathrm{NCl04)}$ 